\title{
Disordered oesophageal motility in thyrotoxic myopathy
}

\author{
M.C.M. Sweatman* and L. Chambers \\ Edgware General Hospital, Edgware, Middlesex, HA8 OAD, UK.
}

\begin{abstract}
Summary: Dysphagia is an uncommon feature of thyrotoxic myopathy, and is usually associated with other signs of bulbar weakness, such as dysarthria and nasal regurgitation. We report a case of thyrotoxicosis presenting with dysphagia due to diminished oesophageal motility associated with significant hypercalcaemia; both abnormalities resolved rapidly following treatment.
\end{abstract}

\section{Introduction}

Chronic thyrotoxic myopathy was initially considered rare (Waldenstrom, 1945; Whitfield \& Hudson, 1961), but with the advent of electromyography it has become apparent that myopathy to some extent is virtually ubiquitous among thyrotoxic patients (Havard et al., 1963; Satoyoshi et al., 1963a; Ramsay, 1966). This report describes a rare presentation of thyrotoxic myopathy and reviews briefly bulbar and oesophageal involvement in such patients.

\section{Case report}

A 71 year old woman presented with a 3 month history of dysphagia, associated with a sensation of solid food sticking at the lower retrosternal region, and anorexia. There was no history of nasal regurgitation and speech had remained normal; she had lost $1 \frac{1}{2}$ stones in weight during this time. Three weeks before admission she had fallen, and afterwards noticed progressive muscle weakness, such that she could not rise from a sitting or lying position, climb stairs or lift objects above her head.

She had received iodine therapy for thyrotoxicosis presenting with a goitre at the age of $18 \mathrm{y}$ and further medical treatment for a recurrence of exophthalmos at $38 \mathrm{y}$.

On admission there was bilateral symmetrical weakness of neck and trunk flexion and profound symmetrical muscle weakness in the upper and lower limbs mainly affecting proximal muscles but with some distal involvement in the upper limbs. There was wasting of the small muscles of the hand. Reflexes were brisk and symmetrical with a left flexor and right

\footnotetext{
*Correspondence and present address: M.C.M. Sweatman B.Sc., M.B., M.R.C.P., Cardiothoracic Institute, Brompton Hospital, Fulham Road, London SW3 6HP, UK.

Accepted: 8 November 1984
}

equivocal plantar response. Tone, sensation and coordination were normal.

Full blood count, urea, electrolyte, blood sugar and creatine kinase estimations were normal. Serum calcium was elevated to $3.08 \mathrm{mmol} / 1$ corrected. Serum phosphate was $1.42 \mathrm{mmol} / \mathrm{l}$ and serum albumin $32 \mathrm{~g} / 1$. A Tensilon test was equivocal on one occasion and negative when repeated. Barium swallow and meal revealed unequivocally diminished oesophageal peristaltic activity, with no other lesion.

A tentative diagnosis of thyrotoxic myopathy presenting with dysphagia was confirmed by the finding of a serum thyroxine of $258 \mathrm{nmol} / \mathrm{l}$. Autoantibodies to thyroid microsomal fraction were demonstrated at one in a hundred dilution.

Electromyography revealed a frankly myopathic pattern in all sampled muscles; nerve conduction studies confirmed normal sensory and motor conduction and there was no evidence of neuromuscular blockade.

Following treatment with carbimazole, $15 \mathrm{mg}$ t.d.s., serum calcium rapidly returned to normal and the dysphagia recovered. The proximal myopathy resolved within 6 weeks and the patient has remained well since that time.

\section{Discussion}

Bulbar involvement is considered a rare manifestation of thyrotoxicosis (Havard, 1962; Ramsay, 1966; Gaan, 1967; Clements et al., 1981), being found in only $55(21.1 \%)$ of approximately 261 patients with thyrotoxic myopathy reported since 1894 . Thirty-six of these patients experienced dysphagia, but 15 had either proven or clinically probable myasthenia gravis. Dysphagia occurred as the only manifestation of bulbar involvement in 12 thyrotoxic patients, though as the sole presenting myopathic feature in only one, 
associated with recurrent aspiration pneumonia (Marks et al., 1980). Barium studies in 7 patients showed pharyngeal weakness in 5 (Waldenstrom, 1945; Strong, 1949; Heinrich et al., 1962; Marks et al., 1980 ), and were normal in 2 (Morgan \& Williams, 1940; Gaan, 1967). In one patient with dystrophia myotonica, thyrotoxicosis and dysphagia, manometry revealed marked pharyngeal weakness with absent oesophageal peristalsis, which resolved following carbimazole therapy (Leach, 1962).

Our patient had moderate hypercalcaemia, which was undoubtedly a manifestation of thyrotoxicosis, since the serum calcium was rapidly corrected following treatment. Significant hypercalcaemia and its clinical sequelae are rare in thyrotoxicosis (Hall et al., 1980), and an association with bulbar or oesophageal weakness has never been described.

Loss of oesophageal peristalsis causing dysphagia is an unusual occurrence in thyrotoxic myopathy, and an unlikely chance association, as both resolved rapidly following treatment. The mechanism for this disordered oesophageal motility remains uncertain; Grieve \& Dixon (1983) have described 2 patients with metas-

\section{References}

CLEMENTS, M.R., HAMILTON, D.V. \& SIKLOS, P. (1981). Thyrotoxicosis presenting with choreoathetosis and severe myopathy. Journal of the Royal Society of Medicine, 74, 459.

GAAN, D. (1967). Chronic thyrotoxic myopathy with involvement of respiratory and bulbar muscles. British Medical Journal, 3, 415.

GRIEVE, R.J. \& DIXON, P.F. (1983). Dysphagia: a further symptom of hypercalcaemia? British Medical Journal, 286, 1935.

HALL, R., ANDERSON, J., SMART, G.A. \& BESSER, M. (1980). In Fundamentals of Clinical Endocrinology, p. 173. Pitman Medical: London.

HAVARD, C.W.H. (1962). Thyrotoxic myopathy: a reappraisal and report of three cases. British Medical Journal, i, 440.

HAVARD, C.W.H., CAMPBELL, E.D.R., ROSS, H.B. \& SPENCE, A.W. (1963). Electromyographic and histological findings in the muscles of patients with thyrotoxicosis. Quarterly Journal of Medicine, 32, 145.

HEINRICH, W.D., MCCABE, E.B., NICELY, D.A. \& ELDER, J.C. (1962). Encephalopathic hyperthyroidism manifesting as dysphagia. American Journal of Roentgenology, 88, 336.

LEACH, W. (1962). Generalised muscular diseases presenting tatic squamous carcinoma of the bronchus and hypercalcaemia; both experienced severe dysphagia without mechanical obstruction, though one had mildly impaired pharyngeal muscular co-ordination. They suggested that hypercalcaemia may cause dysphagia by an effect on neurotransmitter release at the neuromuscular junction, since rapid recovery follows correction of the elevated serum calcium

In patients with weight loss, dysphagia, myopathy and hypercalcaemia it is important to distinguish between carcinomatous neuromyopathy and thyrotoxicosis, since the latter is readily amenable to treatment, but if left undiagnosed and untreated, could easily lead to recurrent aspiration pneumonia, with its attendant morbidity.

\section{Acknowledgements}

We are grateful for the help of Dr Peter P. Turner under whose care the patient was admitted, and to Miss $\mathrm{T}$. Chudleigh and Miss A. Van Loen for secretarial assistance.

as pharyngeal dysphagia. Journal of Laryngology, 76, 237. MARKS, P., ANDERSON, J. \& VINCENT, R. (1980) Thyrotoxic myopathy presenting as dysphagia. Post graduate Medical Journal, 56, 669.

MORGAN, H.J. \& WILLIAMS, R.H. (1940). Muscular atrophy and weakness in thyrotoxicosis (thyrotoxic myopathy; exophthalmoplegic ophthalmoplegia). Southern Medical Journal (Bgham, Ala.), 33, 261.

RAMSAY, I.D. (1966). Muscle dysfunction in hyperthyroidism. Lancet, ii, 931.

SATOYOSHI, E., MURAKAMI, K., KOWA, H., KINOSHITA, M., NOGUCHI, K., HOSHINA, S., NISHIYAMA, Y. \& ITO, K. (1963a). Myopathy in thyrotoxicosis, with special emphasis on an effect of potassium ingestion on serum and urinary creatine. Neurology (Minneap.), 13, 645.

STRONG, J.A. (1949). Thyrotoxicosis with ophthalmoplegia myopathy, Wolff-Parkinson-White syndrome, and pericardial friction. Lancet, i, 959.

WALDENSTRÖM, J. (1945). Acute thyrotoxic encephalo- or myopathy, its cause and treatment. Acta Medica Scandinavica, 2i2, 251.

WHITFIELD, A.G.W. \& HUDSON, W.A. (1961). Chronic thyrotoxic myopathy. Quarterly Journal of Medicine, 30, 257. 